\title{
Usage of thermal isolation systems for low-rise buildings as a component of information models
}

\author{
Pavel Gudkov ${ }^{*}$, Pavel Kagan, Anton Pilipenko, E Yu Zhukova, E A Zinovieva, $N$ A \\ Ushakov \\ Moscow State University of Civil Engineering, 26 Yaroslavskoye Sh., Moscow, 129337, Russia
}

\begin{abstract}
The article discusses the possibility of using the criteria of energy saving, cost and comfort as an estimate criterion in the analysis of information modeling technologies for low-rise buildings at the stages of design, implementation and operation. The insulation systems of low-rise buildings, including frame type, are considered as an object of study.

Different types of insulation systems of frame buildings are considered and, as a result, the expediency of using rolled polyethylene foam as an insulating material is established. Its use allows to form a seamless insulating sheath with minimization of heat transfer bridges, as well as to eliminate the use of additional wind-proof and vapor-insulating membranes.

The regularities of the influence of operating factors on the thermal resistance of the insulating shell are established. The data obtained as a result of the implementation of experimental studies allow us to state that low water absorption and low vapor permeability of the insulating layer exclude the possibility of its wetting and degradation of heat-shielding parameters. The stability of the properties of the insulation sheath and the construction of the walls as a whole is ensured during the entire period of operation.
\end{abstract}

\section{Introduction}

Low-rise buildings occupy a significant segment in the construction of housing, public buildings and economic objects. When designing and implementing construction objects, special attention is paid to energy efficiency, embodied in the insulation systems of these objects and in specialized engineering support systems. The main declared goals are, at the same time, a reduction in the cost of operating the facilities (including energy savings and an increase in maintenance-free time and the life cycle of the facility); the creation of comfortable living conditions; creation of favorable conditions for the implementation of technological solutions in the objects of economic purposes; improving the environmental safety of construction and operation of facilities [1-6].

The energy efficiency solutions could be fully embodied in the process of applying the technology of building information modeling (BIM technology).

Corresponding author: gudkovpk@mgsu.ru 
Due the ideology of BIM, based on the content and further use of data model of the construction project throughout the life cycle, with the proper level of detail, the information model may contain a minimum-necessary amount of information required for qualitative automated assessment of the appropriateness of the use of a material in accordance with the declared objectives. As well as, if necessary, a subsequent evaluation of the effectiveness of the application. [7-11]

When designing low-rise buildings, it is crucial to form structures that have declared strength characteristics, reliability, thermal protection and environmental performance. No less important is the economic factor, focused on cost reduction in material and monetary terms.

All of factors may be included into the information model, during its design as constraints.

\section{Methods}

The main structural types of low-rise buildings are the following structural systems: massive wall (monolith, brickwork, masonry from aerated concrete blocks or stones) with external insulation; frame system (on a metal or wooden frame), frameless system based on profiled metal sheet [12-14]. All information about these systems, their design features and properties, as well as information on the source materials that are elements of these systems are necessary components of information models. At the same time, it should be taken into account that in explicit form, inherited information and qualitative indicators are absent in most cases.

The criterion for reducing the heat loss of a specific object is the thermal resistance of the insulating shell of the building, which depends on the heat transfer resistance along the surface of the wall and heat losses through "cold bridges". Practice shows that the best results occur when the wall is insulated from the outside using effective insulation based on mineral wool, extruded polystyrene foam or polyethylene foam.

In low-rise frame construction, the use of rolled polyethylene foam (Fig. 1), which allows to obtain a seamless insulating casing, approaches the trend [15-17].

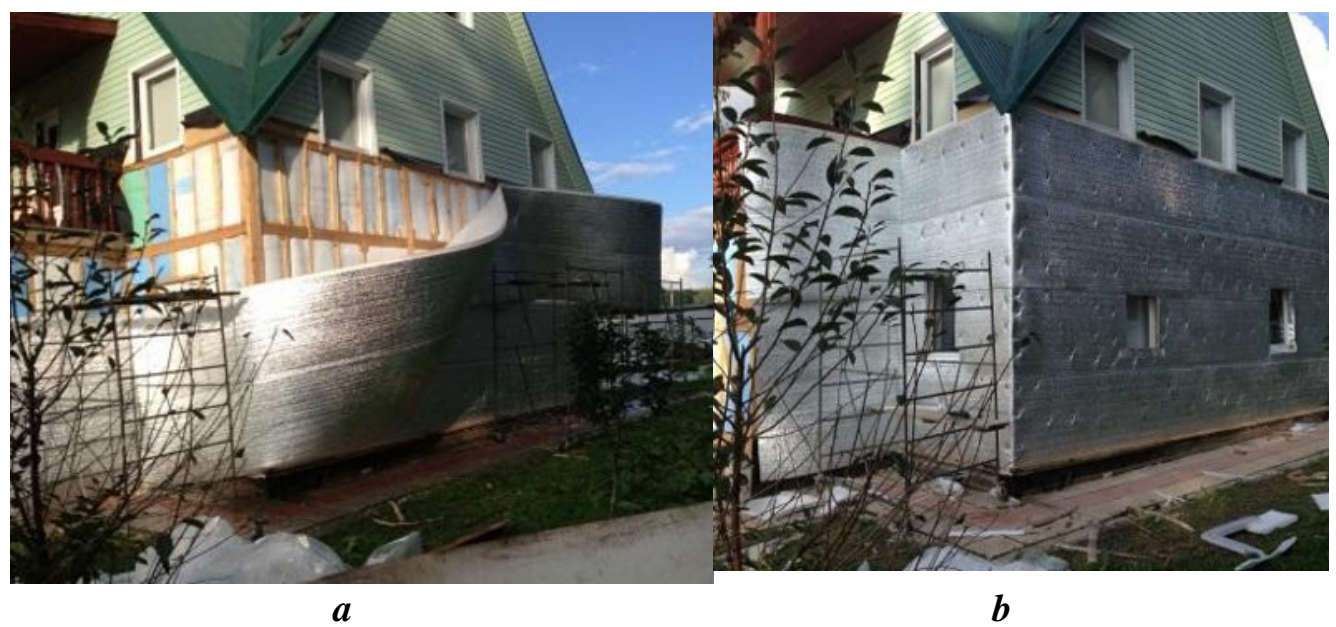

Fig. 1. The formation of the insulating shell of a frame building with the help of rolled polyethylene foam: a - deployment of a roll of IPE; b - for fixing the insulation and stitching the roll of IPE; c formation of an isolation contour and window openings 
To assess the heat-shielding qualities of the outer wall of a wooden frame with insulation by foam polyethylene on the selected wall section, experimental determination of heat transfer resistance was carried out in accordance with GOST 26254-84 "Buildings and Structures. Methods for determining the resistance to heat transfer enclosing structures" and GOST 25380-2014 "Buildings and facilities. Method of measuring the density of heat flux passing through the enclosing structures". The sensors were installed both on the inner and on the outer surface of the wall (Fig. 2).
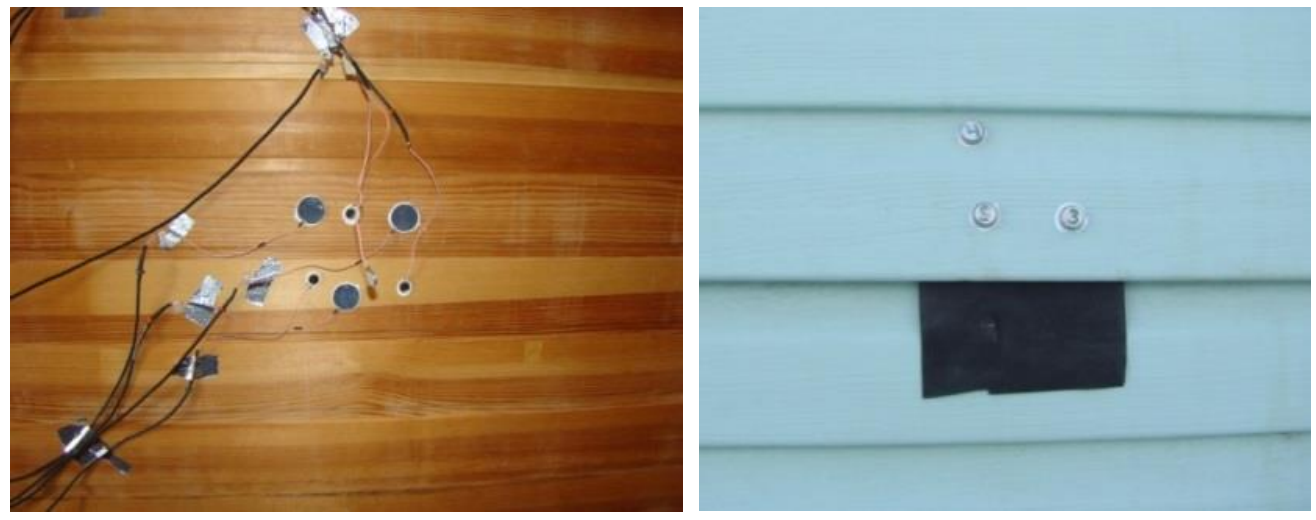

Fig. 2. Installation of temperature and heat flux sensors

No less important for the insulating shell is the fact of the presence or absence of diffusion of water vapor through this shell. Determination of diffusion moisture absorption of foamed polyethylene was carried out in accordance with GOST EN 12088-2011 "Thermal insulation products used in construction".

\section{Results}

The results of experimental determinations of the resistance of an external wall made of a wooden frame with warming with a sheet of foamed polyethylene of the brand were as follows: thermal resistance $2.96 \mathrm{~m}^{2} \cdot{ }^{\circ} \mathrm{C} / \mathrm{W}$, resistance to heat transfer $3.12 \mathrm{~m}^{2} \cdot{ }^{\circ} \mathrm{C} / \mathrm{W}$.

The method for determining the diffusion moisture absorption over a long period of time showed that for samples without coating the diffusion moisture absorption is $0.71 \%$ for a solid sample and $0.75 \%$ for a sample with a seam; and for specimens with reflective coatings, $0.51 \%$ and $0.70 \%$, respectively. Water absorption of samples (with coating and without coating) at partial immersion is $0.012-0.013 \mathrm{~kg} / \mathrm{m}^{2}$, and with full immersion in water in 28 days it does not exceed $0.96 \%$ by volume.

Evaluation of the influence of thermophysical indicators on the value of thermal resistance, and, consequently, on the thermal efficiency of the structure, made it possible to form three main conclusions.

First, obtaining a seamless insulating shell with high thermal performance is possible and can be implemented in construction conditions.

Second, low water absorption and vapor-permeability of the shell on the basis of foam polyethylene eliminates significant changes in thermal resistance in the structure.

Third (and this concerns information bases in the most direct way), when designing structures, two indicators could be recommended as criteria for selecting materials and system solutions for the insulation shell. They are the thermal resistance of the structure and the stability of this indicator over time. Stability also characterizes the minimal degradation of the properties of the insulating sheath throughout the life cycle of the structure. 
In addition, the possibility of direct or indirect transmission of telemetry data from sensors that monitor the status of the indicators under consideration to the information model for their subsequent processing and decision-making at the stages of operation can be promising.

\section{Discussion}

The financial stability is an important factor for the developer or for the consumer in addition to the durability of the building and reducing operating costs. The commercial attractiveness of a particular object (in case of a year-round operation residential cottage) is made up of its price, architectural attractiveness, usable area, operating costs and the stated repair-free operation time.

As a result of comparing various insulation systems for exterior walls of low-rise buildings, it was found that the least expensive and in terms of capital investments in construction and in terms of operating parameters is a frame system. The examples of comparative cost of walls of various designs which can be used to indirectly estimate the cost of construction are shown in table 1 . It does not take into account the design of the roof and the load on the foundation, which are much higher near the walls of aerated concrete blocks and brick walls.

Table 1. Comparative cost of various wall designs

\begin{tabular}{|l|c|c|c|}
\hline \multirow{2}{*}{\multicolumn{1}{|c|}{ Wall system }} & \multicolumn{3}{c|}{ Cost, rubles/m $\mathbf{~}^{2}$} \\
\cline { 2 - 4 } & Materials & Work & Total \\
\hline Plastering system with insulation & $2600-2700$ & $2400-2500$ & $5000-5200$ \\
\hline Wall of aerated concrete blocks & $2200-2300$ & $2200-2300$ & $4400-4600$ \\
\hline $\begin{array}{l}\text { Frame system with insulation } \\
\text { based on mineral wool }\end{array}$ & $700-750$ & $900-1050$ & $1600-1800$ \\
\hline $\begin{array}{l}\text { Frame system with insulation } \\
\text { based on polyethylene foam }\end{array}$ & $700-750$ & $700-850$ & $1400-1600$ \\
\hline
\end{tabular}

Insulation systems for frame buildings with the use of mineral wool board products suggest (Fig. 3) mandatory vapor barrier from the inside and windscreen from the outside. This reduces the movement of the vapor-air mixture through the wall, and the use of additional insulating layers complicates the design and increases its cost (see Table 1). A seamless insulating sheath based on polyethylene foam is made in one layer, which allows to optimize installation and operation costs, as well as increases the durability of the insulation system. 


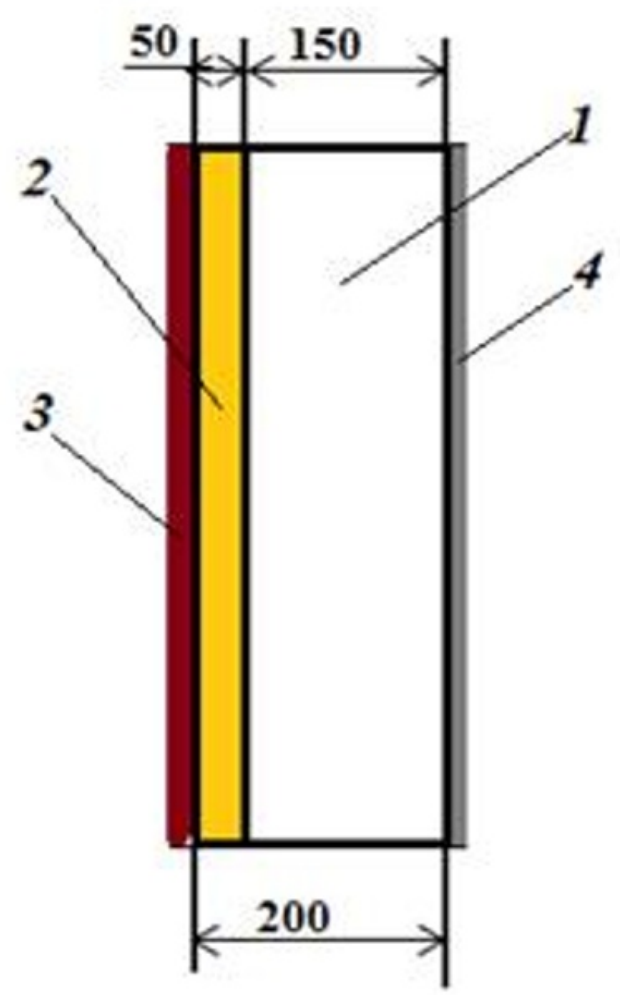

a

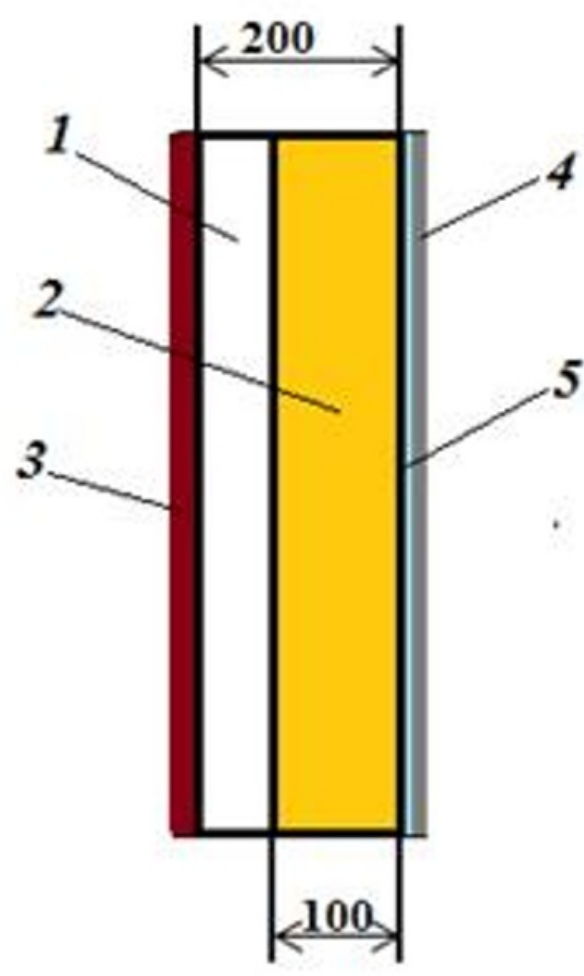

b

Fig. 3. Design schemes of facades with a frame wall: a - thermal insulation of unstitched polyethylene; $b$ - mineral wool insulation; 1 - wood frame element; 2 - heat insulation; 3 - outer lining; 4 - inner lining; 5 - vapor barrier

\section{Conclusions}

One of the main criteria for the maturity of informational submodels is the degree of integration ensured by the programs responsible for the different stages or sides of a single stage of the life cycle of a construction object. One of the conditions for legitimate integration is the existence of criteria for assessing the suitability and adequacy of the selected subsystems that evaluate the various stages of the life cycle. In particular, at the stages of design, construction and operation of the object.

The conducted studies allow to recommend the following factors to be used as evaluative indicators and "reference points" when choosing construction solutions and insulation systems for residential cottages throughout the year - cost of materials and installation of structures and operating costs.

This work was financially supported by Ministry of Science and Higher Education of the Russian Federation (\#NSh-3492.2018.8).

\section{References}

1. V. I. Telichenko, D.V. Oreshkin. Material science aspects of geoecological and ecological safety in construction // Ecology of urbanized areas No. 2 Pp. 31-33 (2015) 
2. P.M. Zhuk, A.D. Zhukov The regulatory legal framework for the environmental assessment of building materials: prospects for improvement // Ecology and Industry of Russia 22, No.4 pp. 52-57 (2018)

3. B.M. Rumyantsev, A.D. Zhukov, T.V. Smirnova Thermal conductivity of high-porous materials // Vestnik MGSU No.3 Pp. 108-114 (2012)

4. Zhukov A.D., Bessonov I.V., Sapelin A.N., Mustafaev R.M. Composite porosity materials / Industrial and civil engineering No.6 Pp. 58-61 (2014)

5. N.P. Umnyakova V.M. Tsygankov, V.A. Kuzmin Experimental heat engineering studies for rational design of wall structures with reflective heat insulation // Housing construction Vol. 1-2 Pp. 38-42 (2018)

6. B.M Rumiantcev, A.D. Zhukov, D.B. Zelenshikov, A.S. Chkunin, K.K. Ivanov, Yu. V. Sazonova Insulation systems of the building construtions / MATEC Web of Conferences 86 (2016). DOI: http://dx.doi.org/10.1051/matecconf/ 20168604027

7. A. Dolganov, P. Kagan On the design of high-rise buildings with a specified level of reliability // E3S Web of Conferences 33 pp. 02061 (2018)

8. P. Kagan, A. Naumova, Y. Vilman The problems of project management software implementation in construction corporations // MATEC Web of Conferences 73 pp. 07016 (2016)

9. P. Kagan The engineering communication networks - the issues of use of standards for information representation in design, construction and operation // Procedia Engineering 153 pp. 261-265 (2016)

10. P. Gudkov, P. Kagan Lavels of data integration in building information modelling // Sistemotehnika stroitel'stva. Kiberfizicheskie stroitel'nye sistemy Sbornik materialov seminara, provodimogo v ramkah VI Mezhdunarodnoj nauchnoj konferencii pp. 68-73 (2018)

11.P.B. Kagan Analytical Studies of BIG Data in Construction // Promyshlennoe I grazhdanskoe stroitelstvo No. 3 pp. 80-84 (2018)

12. A.D. Zhukov, K.A. Ter-Zakaryan, V.S. Semenov Insulation systems with the expanded polyethylene application // IFAC PaperOnLine 51 pp. 803-807 (2018)

13. A. Zhukov, V. Semyonov, I. Gnip, S.Vaitkus. The investigation of expanded polystyrene creep behavior // MATEC Web of Conferences 117001842 (2018)

14. I. Ya Gnip, V.I. Kerchulis, S.Ya. Vaitkus Confidence intervals predicting the creep deformation of polystyrene foam // Construction materials No. 12. pp. 40-44. (2012)

15. A.D. Zhukov, K.A. Ter-Zakaryan, V.S. Semenov, S.D. Kozlov, E.A. Zinovieva, E.D. Fomina Insulation systems for buildings and structures based on polyethylene foam // MATEC Web of Conferences 25101014 (2018)

16. A.D. Zhukov, K,A, Ter-Zakaryan, A.V. Zayafarov, Ye.S. Petrovsky, D.U. Tuchaev // Insulation systems for pitched roofs, Roofs and roofs No.6 pp. 27-29 (2017)

17. I.J Gnip, V. J. Keršulis, S.J. Vaitkus Analytical description of the creep of expanded polystyrene under compressive loading // Mechanics of Composite materials $41 \mathrm{pp}$. 357-364 (2005) 